ESTUDIOS 



\title{
CONSTITUCIONALISMO TRANSNACIONAL: LA CONTRIBUCIÓN DE LA COMISIÓN DE VENECIA ${ }^{1}$
}

\author{
PAUL CRAIG \\ Catedrático de Derecho Inglés \\ Universidad de Oxford
}

\begin{abstract}
SUMARIO
I. Fundamentos y organización. II. Áreas de actuación y funciones. III. Competencia y metodología. IV. La Comisión de Venecia, los órdenes legales transnacionales y la elaboración de una Constitución. V. La Comisión de Venecia, proceso y sustancia. VI. La Comisión de Venecia, cumplimiento e impacto. VII. Conclusión
\end{abstract}

Este artículo examina la contribución al constitucionalismo transnacional de la Comisión Europea para la Democracia a través del Derecho, comúnmente llamada Comisión de Venecia. Dicha Comisión pertenece al Consejo de Europa, pero es menos conocida que el Tribunal Europeo de Derechos Humanos (TEDH), a pesar de que ya hay bastante bibliografía sobre ella ${ }^{2}$. Este artículo no sólo pretende explicar, sino también evaluar su funcionamiento e incidencia.

1 Catedrático de Derecho inglés, St. John's College, Universidad de Oxford. Representante suplente del Reino Unido en la Comisión de Venecia. El artículo refleja sólo las opiniones del autor. Agradezco los comentarios de los participantes en la conferencia de la Facultad de Derecho de UC Irvina, como también los de Greg Shaffer, Terry Halliday y Tom Ginsburg. Traducción de Núria González Campañá, doctoranda de Derecho de la UE de la Universidad de Oxford.

2 Ver, p.ej., Buquicchio, G. y Garrone, P., 'L’harmonisation du droit constitutionnel européen: La contribution de la Commission européenne pour la démocratie par le droit' (1998) 3 Uniform Law Review/ Revue de Droit Uniforme 323; Bartole, S. , 'Final Remarks: The Role of the Venice Commission' (2000) 26 Review of Central and East European Law 351; MALinverni, G. , 'La reconciliation a travers l'assistance constitutionnelle aux pays de l'Europe de l'est: le role de la Commission de Venise' (2004) 10 Les Cabiers de la Paix 207 (2004); Buquicchio, G. - Durr, S., 'The Venice Commission's Action in Africa', en Yazici, S., Kemal, G. y GozTepe, E. (eds.), Essays in Honour of Ergun Ozbudun (Ankara: Yetkin, 2008), Vol II, p. 165; G. Buquicchio, 'Vingt ans avec A. La Pergola pour le développement de la démocratie', en VAn Dijk, P. y GranAta-Menghini, S. (eds.), Liber amicorum Antonio La Pergola (Lund: Juristförlaget I, 2009), p. 29; BuQUICchio, G. y Granata-Menghini, S., 'The Venice Commission Twenty Years on, Challenges met, but 
El artículo explica primero la organización de la Comisión de Venecia y seguidamente analiza sus áreas de actuación y sus funciones. Después se examina su metodología de trabajo. El resto del artículo evalúa el papel de la Comisión en relación con el constitucionalismo entendido en un sentido amplio, analizándose en el marco de la bibliografía existente sobre órdenes legales transnacionales $(\mathrm{OLTs})^{3}$. Se realiza una somera aproximación a las tesis principales de la teoría sobre OLTs, las razones por las que la Comisión de Venecia puede ser conceptualizada dentro de este marco teórico, y su contribución distintiva al constitucionalismo. Los OLTs, de manera creciente, están presentes en diversas áreas, incluyendo aquellos relativos a las constituciones, la democracia, los derechos humanos y el Estado de Derecho. Resulta todavía más interesante que los OLTs estén sujetos al mismo tipo de evaluación que tenemos en mente cuando pensamos en normas nacionales. Es por ello que el artículo incluye un análisis detallado de los derechos procesales y el procedimiento que se sigue cuando un Estado es objeto de una opinión de la Comisión de Venecia. También se revisan los criterios sustantivos y estándares que la Comisión debe tener en cuenta cuando prepara sus opiniones. El capítulo concluye examinando cómo se recibe la opinión en el Estado destinatario y el impacto general de la Comisión a través de la cooperación y de compartir las «mejores prácticas».

\section{FUNDAMENTOS Y ORGANIZACIÓN}

El impulso para la creación de la Comisión de Venecia vino de la mano de Antonio La Pergola, Ministro italiano de Asuntos Europeos, quien, a finales de la década de los ochenta, planteó la posibilidad de crear un órgano que monitorizara el respeto a la democracia y al Estado de Derecho. Recordemos el contexto político del momento: colapso del régimen comunista polaco en 1989, caída del muro de Berlín en noviembre del mismo año y expulsión de gobiernos comunistas en Checoslovaquia, Rumanía, Bulgaria y Albania en los dos siguientes años. La Pergola organizó una conferencia en Venecia en enero de 1990 en la cual participaron miembros del Consejo de Europa, acompañados por observadores de países de Europa Central y del Este. Dicha reunión fue el catalizador para la

Challenges Ahead', Van Roosmalen, M., Vermeulen, B., Van Hoof, F., Oosting, M. (eds.), Fundamental Rights and Principles, Liber Amicorum Pieter van Dijk (Cambridge: Intersentia, 2013), p. 241; DE VISSER, M. 'A Critical Assessment of the Role of the Venice Commission in the Processes of Domestic Constitutional Reform' (2015) 63 American Journal of Comparative Law 963; HofFMANN-RIEM, W. 'The Venice Commission of the Council of Europe - Standards and Impact (2014) 25 EJIL 579; BARTOLE, S., 'International Constitutionalism and Conditionality, 'The Experience of the Venice Commission', Rivista Associazone Italiana dei Costituzionalisti. 4/2014.

3 Halliday, T. C. y Shaffer, G. (eds.), Transnational Legal Orders (New York: Cambridge University Press, 2015). 
creación de la Comisión de Venecia ${ }^{4}$, firmándose un acuerdo inicial para los dos siguientes años ${ }^{5}$. La condición de miembro se reservó al principio para Estados que fueran parte del Consejo de Europa.

El actual Estatuto de la Comisión, que data del año 2002, permite que Estados no miembros del Consejo de Europa puedan ser parte de la Comisión de Venecia $^{6}$, que ahora reúne a 61 Estados, entre ellos los 47 países que pertenecen al Consejo de Europa, más otros 13 países ${ }^{7}$. La Comisión se financia con un presupuesto al que contribuyen los Estados miembros, que ha de acordarse por el Comité de Ministros del Consejo de Europa ${ }^{8}$.

Su secretariado permanente, que presta asistencia a la Comisión ${ }^{9}$, se encuentra en Estrasburgo en la sede del Consejo de Europa. Las sesiones plenarias se celebran en Venecia cuatro veces al año, para las cuales el secretariado prepara la agenda y los materiales de apoyo ${ }^{10}$, que normalmente se distribuyen con dos semanas de antelación ${ }^{11}$. La Comisión de la Unión Europea participa en las sesiones plenarias de la Comisión de Venecia. También lo hace la Organización para la Seguridad y la Cooperación en Europa (OSCE) ${ }^{12}$, y la oficina de la OSCE para Instituciones Democráticas y Derechos Humanos (OIDDH) ${ }^{13}$, la cual asimismo participa en las subcomisiones de la Comisión de Venecia.

La Comisión de Venecia escoge, para un mandato de dos años renovable, a un Bureau o directiva, compuesto de un Presidente, tres Vice-Presidentes y cuatro miembros más ${ }^{14}$. El presidente preside el trabajo de la Comisión y la representa $^{15}$. Hay sub-comisiones que tratan sobre derechos fundamentales, estados federales y estados regionales, derecho internacional, protección de las minorías, el poder judicial, instituciones democráticas, métodos de trabajo, América Latina, la cuenca mediterránea, el Estado de Derecho y la igualdad de género. Las opiniones y los informes son discutidos por la sub-comisión correspondiente antes de su consideración en el pleno ${ }^{16}$. Hay también un Consejo conjunto sobre Justicia

4 http://www.venice.coe.int/webforms/events/

5 El Comité de Ministros del Consejo de Europa estableció la Comisión de Venecia a través de la Res. 90(6) adoptada el 10 de mayo de 1990, que contenía el estatuto original de la Comisión de Venecia.

6 Resolución Res. (2002) 3 Adopta el Estatuto Revisado de la Comisión Europea para la democracia a través del Derecho, CDL (2002) 27.

7 Argelia, Brasil, Costa Rica, Chile, Israel, Kazajistán, la República de Corea, Kosovo, Kyrgyzstan, Marruecos, México, Perú, Túnez y los EEUU. Corresponde al Comité de Ministros del Consejo de Europa invitar a un Estado no miembro a participar en la Comisión de Venecia, Estatuto Revisado (n 5) Art 2.5.

8 Estatuto Revisado (n 5) Art 6.1.

9 Estatuto Revisado (n 5) Art 8; Normas Procedimentales Revisadas, CDL-AD(2015)044, Art. 7.

10 Normas Procedimentales Revisadas (n 8) Art 8.1.

11 Normas Procedimentales Revisadas (n 8) Art 9.1.

12 http://www.osce.org/.

13 http://www.osce.org/odihr.

14 Estatuto Revisado (n 5) Art 4.

15 Normas Procedimentales Revisadas (n 8) Art 6. Gianni Buquicchio es el Presidente desde el mes de diciembre de 2009.

16 Directrices relativas a los Métodos de Trabajo de la Comisión, CDL-AD(2010)034, II.D. 
Constitucional, y un Consejo sobre Elecciones Democráticas, que se explican más adelante. Asimismo, hay también un Consejo Científico, compuesto por el Presidente y los Vice-Presidentes de la Comisión; los que presiden las Sub-Comisiones; y miembros que dirigen los centros de investigación sobre derecho constitucional, internacional y de los derechos humanos. Dicho Consejo Científico prepara compilaciones de la doctrina de la Comisión en áreas específicas; evalúa el nivel de implementación de las opiniones e informes de la Comisión; propone los estudios que se deberían llevar a cabo; y proporciona a los relatores material para la preparación de sus opiniones e informes ${ }^{17}$.

La condición de miembro de la Comisión de Venecia se regula en el artículo 2 del estatuto. Dicho artículo establece que la Comisión se compondrá de «expertos independientes que hayan adquirido eminencia gracias a su experiencia en instituciones democráticas o por su contribución al desarrollo del derecho y la ciencia política» ${ }^{18}$. Los miembros individuales de la Comisión participan a título personal $\mathrm{y}$ «no deben recibir o aceptar ningún tipo de instrucciones» ${ }^{19}$. Son nombrados por sus respectivos países y ocupan el cargo, renovable, durante cuatro $a_{n ̃ o s}{ }^{20}$. Los miembros individuales suelen ser profesores de derecho público y derecho internacional, jueces nacionales, abogados en ejercicio, miembros de parlamentos nacionales y funcionarios. Los representantes del Comité de Ministros, de la Asamblea Parlamentaria del Consejo de Europa, del Congreso de Autoridades Locales y Regionales Europeas y de la «Giunta» o Consejo de gobierno de la región del Veneto pueden asistir a las sesiones de la Comisión ${ }^{21}$. La Unión Europea también está «facultada» para participar en el trabajo de la Comisión ${ }^{22}$, y el Comité de Ministros puede autorizar a la Comisión para que invite a organizaciones internacionales a participar en sus trabajos ${ }^{23}$. La Comisión de Venecia tiene también la posibilidad de contratar a consultores para facilitar la consecución de sus objetivos ${ }^{24}$.

\section{II. ÁREAS DE ACTUACIÓN Y FUNCIONES}

El papel de la Comisión de Venecia se establece en el Artículo 1.1 del Estatuto, que prescribe los siguientes objetivos: fortalecer el conocimiento de los sistemas legales de los Estados miembros, con la intención de aproximarlos;

17 Ibid II.C; Normas Procedimentales Revisadas (n 8) Art. 17a..

18 Estatuto Revisado (n 5) Art 2.1.

19 Ibid Art 2.1.

20 Ibid Arts 2.2-2.3.

21 Ibid Art 2.4.

22 Ibid Art 2.6.

23 Ibid Art 2.7

24 Ibid Art 5. 
promover el Estado de Derecho y la democracia; y examinar los problemas suscitados por el funcionamiento de las instituciones democráticas, así como su fortalecimiento y desarrollo. El Artículo 1.2 indica que la Comisión debe priorizar el trabajo concerniente a los principios constitucionales, legislativos y administrativos, así como las técnicas que sirven tanto para la eficiencia de las instituciones democráticas y su fortalecimiento como para el Estado de Derecho; los derechos fundamentales y libertades; y la contribución de los gobiernos autónomos locales y regionales para el mejoramiento de la democracia. Lo cierto es que la Comisión de Venecia trabaja, sobre todo, en tres grandes áreas.

\section{(a) Instituciones democráticas y derechos fundamentales}

La primera gran área se refiere a instituciones democráticas y derechos fundamentales, lo cual incluye ${ }^{25}$ : relaciones entre los diferentes poderes del Estado; cooperación inter-institucional; Estado de Derecho; reforma judicial; protección de derechos fundamentales; protección de minorías; poderes en situaciones de emergencia; inmunidad parlamentaria; instituciones de defensoría del pueblo; descentralización; federalismo y regionalismo; y la interacción entre derecho internacional y derechos humanos.

La reforma constitucional también es un tema central en el trabajo de la Comisión de Venecia, incluyendo tanto la elaboración de constituciones como las modificaciones constitucionales, así como la legislación de naturaleza constitucional. La Comisión de Venecia también se preocupa del funcionamiento de las instituciones políticas, del equilibrio de poder entre los principales órganos del Estado y del marco legal de los sistemas judiciales nacionales. Asimismo, las opiniones sobre derechos fundamentales también constituyen una parte significativa del trabajo de la Comisión, preocupándose, sobre todo, por si las normas nacionales relativas a derechos fundamentales, como la libertad de expresión, se adecúan a los estándares europeos e internacionales.

\section{(b) Justicia Constitucional}

La segunda gran área de trabajo para la Comisión de Venecia es la justicia constitucional $^{26}$. Desde sus inicios ha facilitado el diálogo entre tribunales constitucionales. Prueba de ello es la creación en el año 1992 de un centro de documentación para promover el intercambio de información entre tribunales y para informar al público de sus sentencias. La Comisión estableció una red de

25 http://www.venice.coe.int/WebForms/pages/?p=01_Const_Assistance\&lang=EN.

26 http://www.venice.coe.int/WebForms/pages/?p=01_Constitutional_Justice\&lang=EN. 
funcionarios de enlace en los diversos tribunales constitucionales. Dichos funcionarios contribuyen tres veces al año al Boletín de Sentencias Constitucionales y a la base de datos de la Comisión CODICES ${ }^{27}$. Hay un servicio, el 'Forum Venecia', que promueve el intercambio de información entre tribunales sobre asuntos en discusión.

La cooperación entre los tribunales constitucionales y la Comisión de Venecia se institucionalizó después de 2002 a través del Consejo Conjunto sobre Justicia Constitucional, (JCCJ por sus siglas en inglés) ${ }^{28}$. El JCCJ está copresidido: un presidente es miembro de la Comisión, mientras que el otro es un funcionario de enlace elegido por el resto de funcionarios en una reunión de la JCCJ ${ }^{29}$. La Comisión de Venecia invita a tribunales constitucionales y a tribunales de jurisdicción equivalente de sus Estados miembro, Estados miembro asociados, Estados observadores y Estados con un estatus especial de cooperación (como por ejemplo Sudáfrica y Palestina) a participar en el JCCJ. Tribunales de otros Estados pueden ser invitados a las reuniones del JCCJ como invitados especiales.

Así, el JCCJ es el órgano de dirección en la cooperación entre la Comisión de Venecia y los Tribunales Constitucionales. Publica el Boletín de Jurisprudencia Constitucional $^{30}$, que, desde 1993 , contiene resúmenes de las sentencias más importantes de los Tribunales Constitucionales de cerca de 50 países, el TEDH, y el Tribunal de Justicia de la UE (TJUE). El JCCJ también supervisa la base de datos CODICES, que se actualiza tres veces al año. Incluye cerca de 4000 resúmenes que también se publican en el Boletín, y el texto completo de aproximadamente 5000 decisiones. El boletín y la base de datos CODICES ponen a disposición del público decisiones constitucionales de muchos países que de otro modo serían inaccesibles. Ello facilita la investigación y ofrece a los tribunales constitucionales la posibilidad de conocer cómo se han tratado determinados problemas en otros países, fomentándose así el intercambio transconstitucional de ideas. A la reunión anual del JCCJ le sigue una conferencia sobre un tema que suscite interés entre los que se dedican a la justicia constitucional.

\section{(c) Elecciones, referéndums y partidos políticos}

El tercer ámbito donde la Comisión de Venecia es muy activa es el relativo a elecciones $^{31}$, referéndums y partidos políticos ${ }^{32}$. El trabajo en este área se

27 http://www.codices.coe.int/NXT/gateway.dll?f=templates\&fn=default.htm.

28 Estatuto Revisado (n 5) Art. 3.4.

29 Normas de Procedimiento Revisadas (n 14) Art. 18.

30 http://www.venice.coe.int/WebForms/pages/?p=02_02_Bulletins.

31 http://www.venice.coe.int/WebForms/pages/?p=01_Elections_and_Referendums\&lang=EN.

32 http://www.venice.coe.int/WebForms/pages/?p=02_parties. 
desarrolla bajo los auspicios del Consejo para Elecciones Democráticas (CDE por sus siglas en inglés), que es un órgano tripartito compuesto por miembros de la Comisión de Venecia, la Asamblea Parlamentaria del Consejo de Europa (PACE), y el Congreso de Autoridades Locales y Regionales del Consejo de Europa. El CDE y la Comisión cooperan con la OSCE/ODIHR. Las opiniones del CDE están sujetas a aprobación del pleno de la Comisión de Venecia de la misma manera que las opiniones sobre otros temas.

El CDE ofrece recomendaciones y proporciona opiniones sobre legislación en materia electoral. La Comisión de Venecia ha adoptado aproximadamente 120 opiniones y ha redactado unos 60 documentos con carácter general sobre elecciones, referéndums y partidos políticos. Se ha prestado especial atención a los códigos de buenas prácticas electorales en materia de referéndums y partidos políticos ${ }^{33}$.

La Comisión también organiza la Conferencia Europea Anual de Órganos de Gestión Electoral, proporciona prácticas y capacitación a aquellas personas involucradas en procesos electorales y participa en algunas misiones de observación electoral $^{34}$.

\section{(d) Lo específico y lo general}

El trabajo de la Comisión de Venecia combina opiniones concernientes a países concretos y estudios generales, que se nutren parcialmente de dichas opiniones y ofrecen recomendaciones sobre determinados derechos fundamentales, con la esperanza de servir de inspiración al legislador, a autoridades públicas, jueces, etc ${ }^{35}$. Relacionados con los estudios generales están las compilaciones de extractos de opiniones adoptadas por la Comisión en áreas concretas ${ }^{36}$. El objetivo es ofrecer una visión general de la doctrina en un ámbito concreto y servir de referencia para el poder constituyente y el legislador ordinario ${ }^{37}$.

33 Ver, p.ej., el Código de Buenas Prácticas en Materia Electoral, CDL-AD(2002)23 rev; Código de Buenas Prácticas en Referéndums, CDL-AD(2007)008; Directrices sobre Regulación de Partidos Políticos, de la OSCE/ODIHR, CDL-AD(2010)024; Código de Buenas Prácticas en el campo de los Partidos Políticos, CDL-AD(2009)021.

34 http://www.venice.coe.int/WebForms/pages/?p=02_seminars.

35 Ver, p.ej., Directrices sobre Modificaciones Legislativas en material de Religión o Creencias, CDL(2004)061; OSCE/ODIHR_Comisión de Venecia Directrices sobre Libertad de reunión pacífica, $2^{\text {a }}$ ed, CDL-AD(2010)020; Comisión de Venecia-OSCE/ODIHR Directrices Conjuntas sobre Libertad de asociación, CDL-AD(2014)046; Informe sobre la Implementación de los Tratados Internacionales de Derechos Humanos en Derecho Interno y el Papel de los Tribunales, CDL-AD(2014)036.

36 http://www.venice.coe.int/WebForms/pages/?p=04_Compilations\&lang=EN.

37 Ver, p.ej., Compilación de Opiniones de la Comisión de Venecia sobre Libertad de asociación, CDL-PI(2014)004; Compilación de la Comisión de Venecia sobre Cláusulas de Reforma Constitucional, CDL-PI(2015)023; Compilación de Opiniones e Informes de la Comisión de Venecia sobre Partidos Políticos, 
Dichas compilaciones facilitan el trabajo de los miembros de la Comisión cuando preparan opiniones sobre países concretos, garantizándose así una aproximación uniforme y constante en todos los documentos de la Comisión.

Las compilaciones siguen un orden temático y se actualizan regularmente. Así, si se toma la compilación sobre libertad de asociación como ejemplo, los principales capítulos son: definición de la libertad de asociación; términos de referencia a nivel nacional e internacional; contenido de la libertad de asociación; expresión de la libertad de asociación; estatus legal y registro de la asociación; disolución de la asociación; organizaciones no gubernamentales; y organizaciones religiosas o de creencias $^{38}$.

\section{COMPETENCIA Y METODOLOGÍA}

\section{(a) Competencia de la Comisión de Venecia}

La Comisión de Venecia tiene la competencia de elaborar informes a iniciativa propia. El artículo 3.1 indica que sin perjuicio de la competencia de los órganos del Consejo de Europa, la 'Comisión puede llevar a cabo investigaciones a iniciativa propia y, si es menester, preparar estudios, borradores de directrices, leyes y acuerdos internacionales'. Cualquier propuesta de la Comisión se puede discutir y adoptar por los órganos del Consejo de Europa.

El artículo 3.2 señala las instituciones/Estados que pueden solicitar una opinión a la Comisión de Venecia en un asunto que sea propio de sus competencias: La Comisión puede proporcionar opiniones, dentro de su ámbito de actuación, a requerimiento del Comité de Ministros, la Asamblea Parlamentaria, el Congreso de Autoridades Locales y Regionales de Europa, el Secretario General, o un Estado u organización internacional que participe en los trabajos de la Comisión. Cuando un Estado solicita una opinión sobre una cuestión relativa a otro Estado, la Comisión informará al Estado afectado y, salvo acuerdo entre las partes, referirá la cuestión al Comité de Ministros.

La realidad es que la mayoría de las opiniones se inician a petición de un Estado parte de la Comisión de Venecia. El Estado puede solicitar asesoramiento en la elaboración de una Constitución, en un proceso de reforma constitucional o simplemente porque detecta deficiencias en determinadas áreas legislativas. La petición a la Comisión de Venecia también se explica en ocasiones por tensiones intra-institucionales a nivel nacional en el Estado solicitante, donde la solicitud de opinión forma parte de una lucha más amplia entre los poderes ejecutivo y

CDL-PI(2016)003; Compilación de Opiniones e Informes de la Comisión de Venecia sobre Igualdad de género, CDL-PI(2016)007.

38 Compilación de las Opiniones de la Comisión de Venecia sobre Libertad de asociación (n 36). 
legislativo o entre partidos políticos rivales. La solicitud en realidad corresponde al partido político al frente del gobierno, y la Comisión se abstiene de indagar en las motivaciones políticas que subyacen a la petición. Aun así, dichas tensiones aflorarán cuando el grupo de trabajo de la Comisión inicie sus tareas. El grupo de trabajo se apoya en la documentación que le proporciona el Secretariado de la Comisión y en la información que se recabe en las visitas de campo que realiza el propio grupo, en el marco de las cuales los miembros de la Comisión designados como relatores de la opinión se entrevistarán con muy diversos actores.

Se podría pensar también, de manera un poco cínica, que las solicitudes a la Comisión de Venecia funcionan a veces como meras apariencias: se pretende ensalzar las credenciales democráticas del país cuando, al mismo tiempo, no se tiene intención de aplicar ninguna de las futuras recomendaciones de la Comisión. La Comisión de Venecia no tiene ningún mecanismo formal para hacer cumplir sus recomendaciones. Sin embargo, se debería ser cauto con este argumento. Puede haber un gran número de razones por las que resulta complicado implementar las recomendaciones, muchas de ellas de buena fe por parte de quien pidió la opinión. Resulta dudoso que un «actor estatal racional» actúe de este modo. Podría parecer sencillo pedir un informe a la Comisión, ser felicitado por ello, y no asumir el coste de implementación si no se tiene intención de llevarla a cabo. Sin embargo, las cosas suelen ser más complicadas. La solicitud a la Comisión, inevitablemente, saca al genio de la botella. La «ley defectuosa» es señalada, minuciosamente analizada y se produce una visita al país en la que los ponentes de la Comisión se entrevistan con variedad de actores, tanto oficiales como no oficiales. El resultado de este proceso no se puede controlar ni predecir y cualquier beneficio aparente o inicial podría ser rápidamente socavado por los costes políticos que se desencadenarían cuando se hiciera evidente que el gobierno no tiene intención de cumplir con las recomendaciones de la Comisión.

Resulta claro del artículo 3.2 que la Comisión de Venecia también puede ser requerida por otros órganos. De hecho, la Asamblea Parlamentaria del Consejo de Europa es el origen de muchas peticiones. Inevitablemente, hay diferencias de «tono y sensibilidad» en las opiniones que no han sido solicitadas por un Estado, especialmente cuando el Estado no desea dicha opinión. En estos casos, la relación entre la Comisión y el Estado puede ser más adversa.

Asimismo, un Estado no parte en la Comisión también puede dirigirse a ella y solicitar al Consejo de Ministros una opinión ${ }^{39}$. La Comisión también puede facilitar informes como amicus curiae, no sobre la constitucionalidad de la norma afectada, sino sobre cuestiones de derecho constitucional comparado o derecho internacional, a petición de un Tribunal Constitucional o del TEDH ${ }^{40}$.

39 Estatuto Revisado (n 5) Artículo 3.3.

40 Vid, p.ej., Informe Amicus Curiae en el caso Santiago Bryson de la Barra et al (sobre crímenes contra la humanidad) para el Tribunal Constitucional del Perú, CDL-AD(2011)041; Informe Amicus Curiae para el Tribunal Constitucional de Georgia sobre la norma non ultra petita en casos de derecho penal, 


\section{(b) Metodología de trabajo de la Comisión de Venecia}

La manera en que se preparan las opiniones se determina por las Directrices sobre Métodos de Trabajo (Guidelines on Working Methods ${ }^{41}$, y por la práctica desarrollado en estos últimos años. Cuando se solicita una opinión a la Comisión, se crea un grupo de trabajo compuesto normalmente por entre cuatro y seis personas. Son los denominados relatores o ponentes, todos ellos miembros de la Comisión de Venecia ${ }^{.42}$. Son escogidos por ser expertos en la materia que aborda la opinión y, por supuesto, por su disponibilidad durante el tiempo en que se prevé que ha de durar el trabajo. La dimensión temporal es verdaderamente relevante. Por diversas circunstancias, las opiniones de la Comisión de Venecia normalmente se han de elaborar en períodos de tiempo muy $\operatorname{cortos}^{.43}$. Los relatores son ayudados por miembros de la Secretaría ${ }^{.44}$. La Secretaría propone el plazo para presentar el borrador de opinión y proporciona información sobre: el trasfondo de la petición de opinión, la legislación nacional, los estándares aplicables y los trabajos previos de la Comisión que pueden ser relevantes en la cuestión ${ }^{45}$.

El borrador lo elaboran los ponentes de manera conjunta con miembros de la Secretaría del siguiente modo: a todos los miembros del grupo de trabajo se les envía el material correspondiente, que se traduce al inglés o al francés. En principio, todos los relatores escriben un informe individual sobre las cuestiones que plantea la petición de opinión. Normalmente no hay colaboración ni contacto entre los ponentes, aunque es posible que el grupo de trabajo se reúna aprovechando alguna sesión de la Comisión ${ }^{46}$. Desde la Secretaría se elabora entonces un borrador de opinión, que integra los informes personales de los relatores. El borrador se circula entre los miembros del grupo de trabajo, que sugieren cambios y modificaciones que, a su vez, se vuelven a circular hasta que se alcanza un consenso entre todos los ponentes. En algunos casos el procedimiento es diferente. Así, cuando la cuestión es muy amplia, como por ejemplo en el caso de la elaboración de una Constitución, a cada ponente se le pueden asignar tareas específicas. Sus informes serán cotejados e integrados por la Secretaría y el borrador de

CDL-AD(2015)016; República de Moldova - Informe Amicus Curiae para el Tribunal Constitucional sobre el derecho a recurso del Estado contra Jueces, CDL-AD(2016)015.

41 http://www.venice.coe.int/WebForms/pages/?p=01_founding_documents\&lang=EN .

42 Cualquier miembro de la Comisión puede hacer notar su interés en ser miembro de un grupo de trabajo, siempre y cuando tenga disponibilidad para participar teniendo en cuenta los plazos previstos. Directrices sobre los Métodos de Trabajo de la Comisión (n 15) II.E.

43 Ibid II.E., que establece que 'los relatores presentarán sus observaciones y las propuestas de texto a su debido tiempo para permitir que la Secretaría prepare un borrador (consolidado) de opinión dentro del plazo previamente acordado.'

44 Ibid II.E.

45 Ibid II.G.

46 Ibid II.E. 
opinión se enviará a todos los ponentes, quienes podrán sugerir modificaciones al texto.

El borrador analiza la cuestión teniendo en cuenta los estándares relevantes, cuyo contenido se explicará más adelante. Es habitual que se realice una visita al país afectado. Dicha visita puede obviarse si ha habido suficientes contactos y diálogo entre la Comisión y el país en cuestión o, por el contrario, porque dicho país no permita la entrada a su territorio a los miembros de la Comisión. En efecto, la Comisión no tiene competencias para entrar en un país sin su consentimiento. En este sentido, pueden darse dificultades cuando el trabajo de la Comisión no ha sido impulsado por el propio país, sino por otra institución. Aunque lo cierto es que en la práctica, incluso en estos supuestos, los Estados suelen permitir las visitas de los miembros de la Comisión de Venecia.

La visita obedece, principalmente, a dos razones. Proporciona una oportunidad al Estado para intervenir y hacer observaciones a las cuestiones planteadas por los miembros del grupo de trabajo de la Comisión. La atención se centra entonces en dichas cuestiones, que son resultado del trabajo de estudio previo realizado por el grupo de trabajo. La visita también permite a los miembros del grupo de trabajo tener contacto con la sociedad civil y con actores afectados. Esto puede resultar especialmente útil cuando la petición de opinión se ha hecho por un órgano diferente al Estado en cuestión. Sin embargo, incluso cuando la petición la realiza el propio Estado, la visita es interesante porque supone una oportunidad para conocer la opinión de organismos no gubernamentales que normalmente ofrecen perspectivas complementarias (y en ocasiones contradictorias) a las del gobierno.

El borrador final de opinión se prepara después de la visita. Se envía a todos los miembros de la Comisión dos semanas antes de la sesión plenaria ${ }^{47}$, incluyendo a los representantes del Estado objeto del informe, quienes, normalmente lo reciben un poco antes que el resto de miembros de la Comisión ${ }^{48}$. Dichas opiniones pueden ser consideradas en la subcomisión, que se reúne el día antes que la sesión plenaria. Puede haber algún tipo de contacto entre los relatores y el Estado afectado antes de la sesión plenaria. Uno de los relatores presenta el borrador de opinión en la sesión plenaria. Entonces es el turno del Estado afectado para hacer comentarios. Comentarios que pueden referirse a la exactitud de los hechos que se relatan en la opinión, a la interpretación jurídica efectuada, a su compatibilidad con los estándares internacionales o, simplemente, el Estado puede poner en cuestión las recomendaciones incluidas en el informe. Una vez el Estado ya ha hecho pública su opinión, el resto de miembros de la sesión pueden intervenir.

El alcance de la discusión en las sesiones plenarias varía mucho. Por una parte tenemos las opiniones solicitadas por un Estado, que suele estar satisfecho

47 Ibid II.E.

48 Cuando la situación nacional interna así lo requiere, el Presidente, de acuerdo con la Secretaría, puede autorizar que la opinión que todavía no ha sido adoptada en el Pleno sea enviada primero a las autoridades nacionales, Ibid II.E. 
con las recomendaciones, sobre todo porque las cuestiones principales se han discutido en las visitas. En estos casos la discusión en el pleno suele ser breve. Por otra parte están las opiniones solicitadas por actores diferentes al Estado afectado, que no suele mostrarse entusiasmado con el escrutinio al que se le somete, sin perjuicio de que haya tenido la oportunidad de expresar su opinión. En tales circunstancias, la discusión en el pleno puede ser más intensa. También hay, por supuesto, situaciones intermedias.

Asimismo, debe enfatizarse que la discusión continúa a lo largo del proceso. Así, si aparece una cuestión discutida o que no se había tenido suficientemente en cuenta, los relatores pueden tomarlo en cuenta y la opinión se aprueba condicionada a ese cambio. Los relatores se reúnen entonces el día de la sesión plenaria, modifican el borrador y lo vuelven a someter al pleno. La opinión se hace pública cuando se adopta por la sesión plenaria y está disponible en la web de la Comisión. La naturaleza dialógica del proceso se percibe en estas afirmaciones de la Comisión incluidas en su página $\mathrm{web}^{49}$ :

La Comisión no pretende imponer las soluciones establecidas en sus opiniones. En realidad, la Comisión adopta una posición no vinculante basada en el diálogo y comparte la experiencia y la práctica de los Estados Miembros implicados. Es por esta razón que un grupo de trabajo visita el Estado afectado por la opinión, para encontrarse con diversos actores y evaluar la situación de la manera más objetiva posible. Las autoridades también pueden dar su opinión sobre los borradores de opinión de la Comisión.

\section{LA COMISIÓN DE VENECIA, LOS ÓRDENES LEGALES TRANSNACIONALES Y LA ELABORACIÓN DE UNA CONSTITUCIÓN}

\section{(a) Órdenes legales transnacionales}

Hasta ahora este artículo ha adoptado principalmente un enfoque descriptivo-explicativo. La atención se centra ahora en la evaluación y se enmarca en la literatura emergente sobre órdenes legales transnacionales, los OLTs. Los OLTs son definidos por Terence Halliday y Greg Shaffer como «un conjunto de normas jurídicas formalizadas y organizaciones y actores asociados que, basándose en criterios de autoridad, ordenan las interpretaciones y prácticas jurídicas en diversas jurisdicciones nacionales» ${ }^{50}$. El término organización asociada es lo suficientemente amplio como para referirse a cualquier formación u organización social, así

49 http://www.venice.coe.int/WebForms/pages/?p=01_activities\&lang=EN.

50 Halliday, T. C. y Shaffer, G. 'Transnational Legal Orders', en Halliday y Shaffer (n 2) 5. 
como también el término actor, que incluye tanto actores individuales como colectivos cuyas actividades traspasen jurisdicciones nacionales.

El concepto de orden dentro de los OLTs se entiende en términos de normas sociales compartidas e instituciones que orientan expectativas sociales, comunicación y comportamiento. Buena parte del orden social se consigue a través del derecho, y «dicho orden social adquiere autoridad cuando las normas legales son aceptadas e institucionalizadas en diversas jurisdicciones nacionales ${ }^{51}$, por medio de las cuales la orientación normativa de los que aplican el Derecho cambia y su comportamiento se ve afectado.

Un OLT es legal «cuando incluye organizaciones o redes legales transnacionales o internacionales, se compromete directa e indirectamente con múltiples instituciones legales locales y nacionales, y asume una forma legal reconocible» ${ }^{52}$. Las normas legales transnacionales resultantes «pueden reflejar normas nacionales preexistentes, como las de Estados nación importantes, o pueden reflejar normas desarrolladas por actores privados y redes a través de procesos bottom-up» ${ }^{53}$, de modo que las organizaciones y redes transnacionales son «parte del proceso de formación de normas jurídicas, transferencia e institucionalización potencial» ${ }^{54}$. Para Halliday y Shaffer la dimensión legal de los OLTs no exige, no obstante, «jerarquía de normas, ni tampoco es siempre jurídicamente vinculante, ni está invariablemente apoyada por la coerción» ${ }^{55}$.

Un orden legal así definido es transnacional en la medida en que ordena relaciones sociales que de alguna manera van más allá del Estado nación. Resulta claro, además, que «los OLTs abarcan órdenes legales que varían en su ámbito geográfico, desde acuerdos bilaterales y multilaterales, pasando por códigos privados transnacionales y órganos de gobernanza regional e incluyendo también órdenes regulatorios globales»" ${ }^{56}$. Los OLTs pueden evolucionar con el tiempo, puede haber más de un OLT sobre un tema en concreto y puede haber debate y controversia entre OLTs sobre los mismos temas o cuando el ámbito de aplicación de OLTs coincide ${ }^{57}$.

Puede haber varios catalizadores para la creación de un OLT ${ }^{58}$. Podría ser, por ejemplo, una controversia entre la regulación nacional y los mercados globales como resultado de cambios en la interdependencia económica. También es posible que el impulso venga de avances tecnológicos. O puede ser el ascenso de ciertos ideales políticos que se consideran centrales para la legitimidad estatal, de

51 Ibid 8.

52 Ibid 11.

53 Ibid 12

54 Ibid 12 .

55 Ibid 18.

56 Ibid 18-19.

57 Ibid 30 .

58 Ibid 32. 
modo que el Estado usa OLTs para promover dichos ideales. La teoría transnacional es recursiva, en el sentido de que integra el estudio de la elaboración del Derecho y su aplicación dentro de un único marco, evaluando cómo «la elaboración y aplicación de normas legales transnacionales entre legisladores locales, nacionales, transnacionales e internacionales y profesionales del Derecho les afecta dinámica y recurrentemente» ${ }^{59}$.

\section{(b) La Comisión de Venecia y los órdenes legales transnacionales}

El estudio de los OLTs proporciona un marco útil para la evaluación de la Comisión de Venecia, que juega un papel transnacional importante en la difusión de normas jurídicas relativas a la democracia, los derechos humanos y el Estado de Derecho. Esto resulta evidente desde tres perspectivas: la función, los miembros y los valores.

\section{(i) Función}

Los orígenes de la Comisión se han incluido en páginas anteriores, al explicar cómo la Comisión forma parte del Consejo de Europa gracias a la iniciativa de Antonio La Pergola. Esta alianza entre la Comisión y el Consejo refuerza la posición de ambos, puesto que desarrollan funciones complementarias. El Consejo de Europa ya era parte de un OLT que promovía los derechos humanos y el Estado de Derecho, sobre todo a través del TEDH. El Tribunal de Estrasburgo, junto con otras instancias judiciales, está principalmente dedicado a «apagar incendios», en el sentido de resolver disputas una vez éstas llegan al Tribunal. Sin embargo, también es cierto que sus sentencias pueden tener cierto efecto en el comportamiento ex ante de los Estados. La Comisión de Venecia ofrece al Consejo de Europa la posibilidad de una intervención generalizada ex ante, por medio de la cual la Comisión puede ofrecer opiniones sobre constituciones y leyes, con el objetivo de prevenir problemas relativos a derechos humanos y Estado de Derecho en un país concreto, o puede sugerir maneras en que dichos problemas pueden ser solventados a través de la reforma de la constitución o la ley origen del problema.

Desde el punto de vista de la naciente Comisión de Venecia, el hecho de tener una vinculación institucional con el Consejo de Europa también era muy beneficioso, no solo porque la Comisión podía hacer uso de los recursos del Consejo de Europa, sino porque significaba que la Comisión no tenía que construir una reputación y una legitimación completamente ex novo. No se trataba de una organización más entre muchas dedicada a la promoción de los derechos humanos.

59 Ibid 38. 
Así, el acuerdo a través del cual la Comisión de Venecia se integraba dentro del Consejo de Europa fortaleció a ambas instituciones. Proporcionó al Consejo la oportunidad de moldear el orden político post-comunista de muchos países europeos a través de los consejos de la Comisión de Venecia, que básicamente promovía el establecimiento de regímenes liberal-democráticos. Esto era considerado como intrínsecamente bueno, y también se percibió de manera más instrumental como una forma de fortalecer las comunidades políticas que habían estado bajo el yugo comunista.

\section{(ii) Miembros}

La relación entre el Consejo de Europa y la Comisión de Venecia también fortaleció este OLT por razón de sus miembros. La Comisión no tuvo que pedir activamente a los Estados europeos su adhesión, ya que podía aprovechar a los miembros actuales del Consejo. Ello proporcionó un primer grupo de Estados miembro y también permitió la expansión hacia los países excomunistas una vez estos se adhirieron al Consejo de Europa durante la década de los años noventa. Además de incrementarse el número de miembros, estos nuevos Estados tenían una mayor inclinación por recurrir a los consejos y al apoyo de la Comisión para asegurarse de que sus nuevas constituciones estaban alineadas con un orden político liberal democrático.

También debe admitirse, sin embargo, que hay algunos países miembros de la Comisión de Venecia, como Rusia, que difícilmente solicitan asistencia y que muy probablemente se resistirían en caso de que se pidiera algún tipo de investigación sobre su ordenamiento jurídico. Esto nos podría llevar a plantear las razones por las que esta clase de países siguen siendo miembros del Consejo de Europa, dado que es precisamente eso lo que determina su pertenencia a la Comisión. La respuesta a esta cuestión nos llevaría más allá de las limitaciones de este artículo. Baste con mencionar que desde la perspectiva racional del actor estatal, Rusia seguramente piense que los beneficios de la condición de miembro superan a los costes, en términos de desafíos contra leyes rusas ante el TEDH y ante la Comisión de Venecia, aunque haya indicios que sugieren que Rusia pretende limitar la acción de estas entidades sin renunciar a la condición del miembro del Consejo de Europa ${ }^{60}$.

Los miembros de la Comisión de Venecia se expandieron después del año 2002, cuando se permitió la adhesión de Estados no parte del Consejo de Europa. El Estatuto de la Comisión de Venecia se revisó en este sentido. El impulso para este cambio vino precisamente por el deseo de algunos Estados de no conformarse con el estatus de observador y de convertirse en miembros plenos de la Comisión.

60 Russian Federation - Final Opinion on the Amendments to the Federal Constitutional Law on the Constitutional Court, CDL-AD(2016)016-e. 
Esta reaccionó entusiásticamente, ya que el aumento de miembros fortalecía su propia posición. Las razones por las que estos Estados querían formar parte de la Comisión de Venecia son diversas: desde el deseo sincero de aprovecharse de los conocimientos de la Comisión para diseñar constituciones y leyes, hasta los beneficios en términos de legitimidad por el hecho de convertirse en miembro. En el caso de los EEUU las razones eran distintas. Ninguno de los dos tipos de razones alegado explica el deseo norteamericano de convertirse en miembro pleno. Probablemente la voluntad de los EEUU se entiende por su deseo de apoyar a una organización que se percibía que reforzaba el mantenimiento del orden liberal democrático y la estabilidad en Europa y países vecinos, lo que es coherente con los objetivos más generales de la política exterior estadounidense.

Los 61 Estados miembros de la Comisión son diversos, y ello ha aumentado la naturaleza recurrente del modo de actuar de la organización. La Comisión, tal y como veremos más adelante, utiliza una mezcla de «hard law» y «soft law» cuando prepara sus informes. La diversidad de los miembros, que se replica dentro de los grupos de trabajo, subraya la necesidad de respetar el pluralismo a la hora de aplicar los valores de la Comisión de Venecia. Asimismo, también sirve como un recordatorio constante de la necesidad de ser consciente de las circunstancias locales a la hora de aplicar dichos valores.

Hay otro aspecto sobre los miembros de la Comisión de Venecia que también fortalece este OLT en relación con la democracia, los derechos humanos y el respeto al Estado de Derecho. Las normas de la Comisión a cerca de la condición de miembro institucionalizan la cooperación con otros actores institucionales preeminentes que también forman parte de este mismo OLT, en especial la Comisión Europea y la OSCE/ODIHR, mientras que al mismo tiempo también se le permite a la Comisión mantener relaciones sobre bases ad hoc con otras instituciones. La relación entre la Comisión de Venecia y la Comisión Europea ha sido especialmente intensa en relación con los problemas sobre el respeto al Estado de Derecho que se han suscitado en algunos países de la UE, como Hungría y Polonia, mientras que la cooperación con la OSCE/ODIHR es habitual en temas electorales.

\section{(iii) Valores}

Los valores promovidos por el Consejo de Europa y la Comisión de Venecia son la democracia, los derechos humanos y el Estado de Derecho. La Comisión de Venecia juega un papel muy importante en este OLT. Es, de acuerdo a la terminología de Halliday y Shaffer, una de las organizaciones asociadas que conforman y modelan con criterio de autoridad la interpretación y la aplicación del derecho en este ámbito. Hay otras muchas organizaciones que también hacen importantes contribuciones al OLT relativo a los derechos humanos y el Estado de Derecho, pero la contribución de la Comisión de Venecia es indudablemente distintiva y ello deriva de su estructura institucional. 
El hecho de que esté formada por dos representantes de cada Estado, junto con el apoyo institucional que brinda la Secretaría, significa que la Comisión es capaz de responder a multitud de peticiones de apoyo de manera puntual y sin excesivas dilaciones. La capacidad institucional de aceptar múltiples peticiones que requieren una evaluación detallada de constituciones nacionales y de legislación compleja en un breve período de tiempo permite a la Comisión hacer una contribución decisiva en esta área.

Esto se ve reforzado por la diversidad de los miembros de la Comisión: aquellos con experiencia en la materia y los que ostentan un conocimiento cultural del país afectado pueden integrar el mismo grupo. Esto ha permitido el desarrollo de bases de datos, compilaciones y documentos similares, que suministran orientaciones en cuestiones particulares como libertad de expresión, de asociación, de reunión y buenas prácticas electorales. La autoridad de las normas que luego formalizan los valores contenidos en estas orientaciones se ve reforzada. La aplicación, sin embargo, tal y como se verá más adelante, dista de ser perfecta. Puede haber divergencias de criterio en cuanto a la correcta aplicación de tales valores en una situación particular, aunque buena parte del debate ocurra dentro del marco de los valores principales de este OLT.

Sin embargo, tal y como Kim Scheppele ha argumentado $^{61}$, hay crecientes evidencias que señalan que hay Estados que se envuelven con el manto del constitucionalismo mientras simultáneamente pretenden menoscabarlo desde dentro. Esto en sí mismo proporciona evidencias interesantes sobre la evolución de los OLTs, ya que si el OLT establecido en un área concreta es amenazado, existe la posibilidad de la emergencia de un OLT rival. La Comisión de Venecia ejemplifica el siguiente principio enunciado por Halliday and Shaffer ${ }^{62}$.

«Es una premisa demostrable de la teoría constructivista de las relaciones internacionales que la habilidad de una organización internacional para promulgar normas ampliamente aceptadas por los Estados probablemente aumentará el poder de la propia organización. Es decir, los propagadores internacionales de normas se convierten en algo más que la suma de intereses de los Estados miembro, se convierten en actores emergentes por derecho propio que ejercen o promueven sus propios intereses y no pueden ser reducidos a una amalgama de delegaciones estatales».

\section{(c) La Comisión de Venecia y las constituciones}

Hay como mínimo cuatro grandes ámbitos en el estudio de las constituciones: la elaboración y los contenidos de la propia constitución; la reforma constitucional;

61 Scheppele, K. 'Worst Practices and the Transnational Legal Order, or (How to Build a Constitutional «Democratorship» in Plain Sight)', próxima publicación.

62 Halliday y Shaffer (n 49) 59. 
la legislación que impacta directa o indirectamente en el sentido y aplicación de las cláusulas constitucionales; y la práctica constitucional, ya sea en forma de convención constitucional o percepción de la constitución por parte de la gente. La elaboración de constituciones en sentido amplio es una parte importante del trabajo de la Comisión de Venecia ${ }^{63}$, y prueba de ello es la multitud de opiniones al respecto ${ }^{64}$. El trabajo de la Comisión de Venecia en esta área depende del requerimiento que le haga un Estado, u otra institución que esté facultada para ello, y ello determinará el ámbito de la opinión. Las opiniones de la Comisión de Venecia se han encargado de tres de cuatro de los ámbitos constitucionales indicados más arriba.

Primero, hay opiniones relativas a la elaboración y contenidos de una constitución, o al menos de partes significativas de la misma. A modo de ejemplo, las opiniones de la Comisión de Venecia sobre Túnez ${ }^{65}$, Islandia ${ }^{66}$, Bosnia Herzegovina $^{67}$, Hungría ${ }^{68}$, Moldovia ${ }^{69}$, y Armenia ${ }^{70}$. Mientras que el ámbito de estas opiniones difiere, estos informes ejemplifican el papel de la Comisión dando consejos y orientaciones sobre una constitución en su conjunto o sobre partes de la constitución que son esenciales para el esquema constitucional de un país.

En segundo lugar, hay también muchas opiniones sobre reformas constitucionales. El proceso de una reforma constitucional suele ser largo y complejo. En algunos países se ha alargado varios años, lo que implica que durante ese período se van introduciendo sucesivas modificaciones. Puede haber diversos catalizadores para este tipo de reformas. En algunos casos al percatarse de que el diseño constitucional inicial era incorrecto; en otros es resultado de nuevas configuraciones políticas que desean rediseñar la arquitectura constitucional e institucional del país; en otros casos los motivos pueden ser más oscuros, como por ejemplo cuando una mayoría determinada pretende reforzar su posición de fuerza o liderazgo a través de reformas constitucionales que limitan el poder judicial ${ }^{71}$. Las opiniones de la Comisión de Venecia sobre el tema se pueden obtener de su compilación sobre reformas constitucionales ${ }^{72}$, y su aproximación conceptual a la reforma constitucional se halla en un informe específico sobre la materia ${ }^{73}$.

63 http://www.venice.coe.int/WebForms/pages/?p=02_Reforms\&lang=EN.

$64 \mathrm{http}: / / \mathrm{www}$.venice. coe.int/webforms/documents/?topic=4\&year=all.

65 Opinión sobre el Borrador Final de la Constitución de la República de Túnez, CDL-AD(2013)032-e.

66 Opinión sobre el Borrador de Nueva Constitución de Islandia, CDL-AD(2013)010-e.

67 Opiniones sobre los regímenes constitucionales de Bosnia-Herzegovina, CDL-INF(1998)015-e.

68 Opinión sobre la nueva Constitución de Hungría, CDL-AD(2011)016-e.

69 Cooperación entre la Comisión de Venecia y la República de Moldova en materia de reforma constitucional, CDL-INF(2001)003-e.

70 Primera Opinión sobre el Borrador de Reforma de la Constitución (Capítulos 1 a 7 y 10) de la República de Armenia, CDL-AD(2015)037-e.

71 SCHEPpele (n 60).

72 Compilación de la Comisión de Venecia sobre Opiniones relativas a cláusulas constituciones en materia de Reforma Constitucional, CDL-PI(2015)023.

73 Informe sobre Reforma Constitucional, CDL-AD(2010)001. 
En tercer lugar, hay un grupo todavía más numeroso de opiniones relativas a legislación que impacta en las previsiones constitucionales. No es fortuito que la web de la Comisión de Venecia respecto a la reforma constitucional incluya, entre otras, las siguientes cuestiones ${ }^{74}$ : pesos y contrapesos entre poderes y el principio de cooperación inter-institucional; delegación del poder legislativo; reforma judicial; garantías del Estado de Derecho y derechos y libertades fundamentales; sistemas electorales; y cuestiones relacionadas con el autogobierno local y la descentralización. Se podría pensar que deberíamos separar la constitución, su elaboración y sus cláusulas del resto. Las influencias que modelan la elaboración de la constitución y el contenido de sus cláusulas son claramente centrales. Sin embargo, enumerar cuántas constituciones contienen artículos de cierto tipo ofrece sólo una ayuda limitada. Tanto desde un punto de vista normativo como desde un punto de vista pragmático es erróneo trazar una línea rígida entre la constitución y la legislación que tiene como objetivo concretar las cláusulas constitucionales. Asimismo, también es engañoso omitir la existencia de la misma previsión en muchas constituciones con aplicación equivalente.

En muchos aspectos, la legislación constitucional es lo que da vida a una constitución. En principio, cuánto más breve es una constitución y cuanto más abstractos sus artículos, mayor papel tendrá la legislación constitucional y la aplicación jurídica a la hora de insuflar contenido a los términos constitucionales. En cualquier caso, dicha legislación es relevante en todas las constituciones, aunque su incidencia pueda variar. La constitución puede contener cláusulas sobre elecciones libres y justas, pero la realidad sólo podrá ser testada si se examinan los detalles de la legislación electoral que concretan los valores enunciados en la constitución. Puede haber laudables garantías constitucionales para partidos políticos, pero conviene saber si la legislación que desarrolla la cuestión impone cargas excesivas para que puedan presentarse a las elecciones. La fuerza de dar protección constitucional a la libertad de expresión puede ser calificada por leyes sobre asociación. La necesidad de ser consciente de la vinculación entre cláusulas constitucionales y legislación de desarrollo es importante en relación con multitud de cuestiones que aparecen en las constituciones, como los principios relativos a la igualdad o el poder judicial, que luego serán concretados en detalle o se verán afectados por leyes. La Comisión de Venecia subraya en sus opiniones la importancia de este vínculo.

Conviene relacionar la discusión precedente con la relativa a los OLTs. Sería posible concebir un OLT que sólo se ocupara de la elaboración de constituciones y de sus contenidos. De acuerdo con la definición de Halliday y Shaffer en este caso identificaríamos «el conjunto de normas jurídicas formalizadas y organizaciones y actores asociados que, basándose en un criterio de autoridad, ofrecen interpretaciones y prácticas jurídicas válidas para diversas jurisdicciones

74 http://www.venice.coe.int/WebForms/pages/?p=02_Reforms\&lang=EN. 
nacionales ${ }^{75}$. Pero lo cierto es que un OLT así concebido estaría excluyendo las segunda y tercera dimensiones explicadas anteriormente. Tampoco casaría bien con el énfasis que se pone en la ley nacional en la literatura sobre OLTs ni con la naturaleza recursiva de la teoría sobre OLTs, que otorga preminencia al modo en que «la elaboración y aplicación de normas legales transnacionales entre legisladores locales, nacionales, transnacionales e internacionales y entre profesionales del Derecho les afecta dinámica y recurrentemente» ${ }^{76}$. Una contribución decisiva hecha por la Comisión de Venecia al constitucionalismo es que proporciona un escaparate para descubrir la interacción entre constitución, reforma constitucional y legislación constitucional, tal y como muchas de las opiniones de la Comisión de Venecia ejemplifican.

\section{LA COMISIÓN DE VENECIA, PROCESO Y SUSTANCIA}

Los OLTS están adquiriendo cada vez más relevancia en diversas áreas, incluyendo el ámbito de las constituciones, la democracia, los derechos humanos y el Estado de Derecho. El hecho de que los OLTs estén sujetos al mismo tipo de evaluación que se usa habitualmente al analizar normas nacionales los hace todavía más importantes. Especialmente cuando el OLT en concreto que analizamos se ocupa de materias particularmente sensibles como los derechos humanos o el Estado de Derecho, cuyo significado, alcance y aplicación pueden ser discutibles. Deberíamos considerar con detenimiento el proceso a través del cual se toman decisiones y los criterios substantivos que se usan cuando se adoptan ${ }^{77}$. Sólo haciendo eso podemos obtener alguna conclusión relevante sobre la contribución normativa de un OLT particular.

\section{(a) Proceso y derechos procesales}

Maartje de Visser ha argumentado que sería conveniente una mayor formalidad procedimental en las opiniones de la Comisión, ya que la actual flexibilidad «puede, de manera casi imperceptible, menoscabar la calidad y utilidad de la asistencia en la elaboración de constituciones ${ }^{78}$. De Visser percibe falta de homogeneidad en el uso de elementos para evaluar borradores de constituciones y le preocupa, por ejemplo, que en una opinión no se tuviera en cuenta una fuente

75 Halliday, C. T. y Shaffer, G., 'Transnational Legal Orders', en Halliday y Shaffer (n 2) 5.

76 Ibid 38.

77 Buena parte de la literatura crítica sobre organizaciones como la Organización Mundial del Comercio que forman parte de un OLT ejerce esta función.

78 DE VisSER (n 1) 965. 
que ella considera relevante ${ }^{79}$. También piensa que debería haber un «marco procedimental más completo que regule el funcionamiento de la Comisión» ${ }^{80}$. Así se podrían incluir los derechos de participación de los países investigados y la composición de los grupos de trabajo. Debería haber una obligación procedimental de llevar a cabo una visita al país afectado y las autoridades nacionales deberían poder hacer comentarios sobre el borrador de opinión después de la visita al país ${ }^{81}$.

Sobre estas sugerencias se pueden hacer los siguientes dos comentarios. Primero, hay un riesgo en esperar demasiada homogeneidad en las evidencias en que se basan los diferentes informes o en las fuentes consideradas en un informe particular. El riesgo es que lo mejor puede ser enemigo de lo bueno. Siempre es posible criticar un informe porque un analista considera que se debería haber tenido más en cuenta una fuente en particular. Deberíamos recordar que las opiniones se escriben en un periodo temporal muy breve y que la mayoría de relatores tiene otras ocupaciones, ya sea como jueces, académicos o abogados. Las opiniones no son tesis doctorales, ni tampoco se pretende que lo sean.

En segundo lugar, sí hay sin embargo razones para evaluar las actuales normas procedimentales y métodos de trabajo, con el fin de mejorarlos. Los derechos procedimentales de los Estados claramente han de ser considerados importantes, dado que la Comisión de Venecia se dedica a asegurar el respeto al Estado de Derecho, uno de cuyos componentes centrales es el principio audi alteram partem. Ahora bien, tomar una decisión sobre el contenido exacto que han de tener los derechos procesales del Estado es complicado. Como siempre, el diablo está en los detalles.

La situación estándar es que la visita tiene lugar de acuerdo con las exigencias mencionadas más arriba. La Secretaría puede indicar al Estado afectado las cuestiones que se estudiarán antes de la visita; si este no es el caso, durante la visita el Estado conoce los motivos que promueven el interés de la Comisión; si existe un borrador de opinión antes de la visita, éste es solo un documento preliminar y por eso no se hace público; cuando la situación nacional así lo exige, el Presidente, tras consultarlo con el Bureau o Directiva, puede autorizar que la opinión de los relatores que todavía no ha sido adoptada sea enviada a las autoridades nacionales antes de la sesión plenaria; el borrador de opinión final se envía al Estado afectado antes del pleno, y los representantes que este envía para la discusión de la opinión tienen la potestad de comentar el contenido del mismo en el pleno, como también en una subcomisión antes del pleno.

El principio audi alteram partem claramente se respeta en la medida en que el Estado tiene la oportunidad de pronunciarse antes de la adopción de la opinión 
por parte del pleno. Además, también existe la posibilidad discrecional de que el Estado reciba la Opinión incluso bastante antes de la sesión plenaria. No es extraño que se introduzcan enmiendas en las opiniones como resultado de los comentarios que se hacen en la sesión plenaria. El Estado también puede expresar su opinión durante la visita al lugar.

La cuestión clave en el debate sobre el reforzamiento de los derechos procesales es, por tanto, si el Estado debería estar facultado para acceder al borrador preliminar antes de que la versión final se termine. El argumento a favor sería que ello permitiría al Estado conocer con más detalle el punto de vista de la Comisión. El argumento en contra es que antes de la finalización del borrador, la opinión es work in progress. Así, la visita puede revelar cuestiones problemáticas que no estaban consideradas como tal antes, y el riesgo es que las autoridades del Estado se resistan entonces a incluirlas en la opinión preliminar. La visita se convertiría así en una «negociación» detallada del borrador inicial, impidiendo la discusión sobre cuestiones relevantes y si ciertos asuntos no son identificados en el borrador de opinión, las autoridades estatales no los mencionarían.

\section{(b) Criterios sustantivos y estándares}

\section{(i) Estándares de hard y soft law}

La Comisión de Venecia normalmente distingue entre estándares de hard y soft law cuando elabora opiniones y estudios.

El paradigma de estándar de hard law es la Convención Europea de Derechos Humanos (CEDH), y la jurisprudencia del TEDH. La jurisprudencia de Estrasburgo permite cierto margen de apreciación en la aplicación de los derechos de la $\mathrm{CEDH}$, garantizando cierto espacio para la heterogeneidad normativa y cultural. Además, el estatus concreto de la jurisprudencia del TEDH para los Estados signatarios los determina el orden jurídico respectivo de dichos Estados.

De acuerdo con lo anterior, se entiende que la adhesión a la CEDH es vinculante como hard law para los Estados parte. El artículo 46.1 de la CEDH impone la obligación vinculante de hacer cumplir las sentencias de Estrasburgo, ya que indica que «las Altas Partes contratantes se obligan a hacer cumplir la sentencia del Tribunal en que hayan sido partes». La fuerza vinculante del mencionado artículo fue enfatizada por el Tribunal en el caso $S_{c o z z a r i}{ }^{82}$, en el que el Tribunal dejó claro que le correspondía al Estado no sólo compensar a aquellos afectados por el caso en cuestión, sino tomar medidas para terminar con el origen de la violación.

82 Scozzari y Giunta v Italy, Appl. nos. 39221/98 y 41963/98, decisión del 13 de julio del 2000, § 249. 
La Comisión de Venecia también hace un uso considerable de estándares de soft law, cuya naturaleza puede variar, tal y como queda claro en estos comentarios de Gianni Buquicchio y Simona Granata-Menghini ${ }^{83}$.

Además de los estándares de hard law, la Comisión de Venecia también analiza el cumplimiento de textos constitucionales y legales teniendo en cuenta estándares de soft law (p.ej. recomendaciones del Comité de Ministros del Consejo de Europa) o mejores prácticas (p. ej, las directrices preparadas por la Comisión de Venecia junto con la Organización para la Seguridad y la Cooperación en Europa (OSCE)/Oficina para Instituciones Democráticas y Derechos Humanos (ODIHR) sobre libertad de reunión, partidos políticos y libertad de religión; son una combinación de estándares de hard law, su interpretación y las mejoras prácticas). La Comisión también examina la oportunidad y la practicabilidad de los modelos constitucionales o legales escogidos. En estas áreas los estándares no son completamente vinculantes y tampoco están formulados en términos unívocos y taxativos. Los Estados disponen de un margen de apreciación mucho más amplio y son libres de elegir su modelo preferido. Cuando hay varias opiniones igualmente en línea con los estándares, tal y como sucede a menudo, no le corresponde a la Comisión expresar sus preferencias, sino solo indicar qué opción se adecua mejor a la situación del país y si podrá ser útil en la práctica.

Este comentario resume adecuadamente la práctica de la Comisión de Venecia. Algunas fuentes son una mezcla de hard y soft law, como las directrices de la Comisión y las compilaciones, que contienen hard law, puesto que se basan en la jurisprudencia de Estrasburgo. El balance entre hard y soft law dentro de una opinión puede variar. Si la cuestión examinada pertenece al ámbito de los derechos humanos, donde hay una amplia jurisprudencia, el hard law será predominante en esa opinión. Si el centro de atención de la opinión son otras cuestiones más amplias sobre diseño constitucional, o la configuración de órganos de gobierno, entonces el soft law ganará más protagonismo.

\section{(ii) Universalidad y pluralidad}

El otro factor que de manera significativa afecta la substancia de los informes es el balance entre universalidad y pluralidad/diversidad, tal y como han señalado varios analistas. Así, Jeffrey Jowell ha indicado que mientras la «Comisión está convencida de que la democracia contiene ciertos estándares absolutos frente a los cuales hay poco margen de desvío», también es sensible a «diferencias culturales y de contexto en que la democracia echa sus raíces» para que así la asistencia prestada «tome en consideración las diferentes situaciones de los países con experiencias y antecedentes diversos. ${ }^{84}$.

83 Buquicchio y Granata-Menghini (n 1) 244.

84 JOWELL (n 1) 682. 
Sergio Bartole se refirió a la misma cuestión al hablar de la aproximación de la Comisión a los países de la Europa central y del Este que estaban llevando a cabo sus transiciones democráticas. Negó que la adhesión a la herencia constitucional europea significara que «las opciones constitucionales de las nuevas democracias estuvieran subordinadas a directrices estrictas proporcionadas por organizaciones internacionales: en realidad la implementación de la herencia constitucional europea implica respeto a la soberanía estatal» ${ }^{85}$, tal y como se manifiesta en el uso de estándares, que permiten opciones diversas al Estado afectado $^{86}$.

De la misma manera, Buquicchio y Granata-Menghini indican que opciones entre, por ejemplo, un régimen parlamentario, presidencial o semi-presidencial, son básicamente cuestiones que ha de decidir el Estado, puesto que cualquiera de estas opciones puede ser compatible con la democracia ${ }^{87}$. Enfatizan que incluso los estándares de hard law son obligaciones de resultado, no de medios. Por eso aconsejan recelar de la tentación de pensar que un modelo que funciona en un país puede ser trasplantado a otro, señalando que antes de considerar la implantación de un modelo procedente de otro país, conviene «comprobar su compatibilidad con el contexto social y político-legal del país en cuestión ${ }^{88}$.

\section{(iii) Crítica y respuesta}

Puede haber diferencias de opinión en cuanto a la evaluación de una opinión determinada de la Comisión. Esto es esperable, dado que la aplicación de preceptos constitucionales abstractos es discutible. De Visser es generalmente crítica con la Comisión, afirmando que su estudio revela «inconsistencias gratuitas en la manera en que se lleva a cabo la evaluación substantiva de textos constitucionales $y$, relacionado con ello, subraya las oportunidades perdidas para ofrecer una asistencia óptima a los ponentes de los textos constitucionales nacionales» ${ }^{89}$. Baste con decir que hablar de «inconsistencias gratuitas» es o bien poco apropiado o es que de Visser está poniendo el listón muy alto para fundamentar su alegación de inconsistencias (y el adjetivo que las acompaña), sobre todo teniendo en cuenta que su análisis se basa en el examen de solo cuatro opiniones.

El núcleo de su argumento es que la Comisión de Venecia corre el riesgo de llevar demasiado lejos el concepto de «herencia constitucional común», alejándose del principio constitucional y fijándose en modos de aplicación excesivamente detallados, lo cual resulta insostenible.

85 BARTOLE, 'Final Remarks' (n 1) 353.

86 Ibid 355.

87 Buquicchio y Granata-Menghini (n 1) 244.

88 Ibid 246.

89 DE VISSER (n 1) 973. 
Así, mientras de Visser reconoce que la Comisión pretende ofrecer asistencia a los Estados proporcionándoles directrices más concretas, también advierte que «un excesivamente amplio catálogo de elementos que en su conjunto constituyen la herencia común es una idea equivocada y podría, a largo plazo, incluso convertirse en una razón para el desencanto con la tarea de la Comisión de Venecia de ofrecer asistencia constitucional ${ }^{90}$, y que un marco analítico más diversificado sería más aconsejable.

El peligro que de Visser ve en cruzar la línea entre principio constitucional e implementación es que «los Estados pueden sentir que su autonomía en el diseño constitucional se ha limitado de manera indebida», haciendo menos probable que Estados asuman las recomendaciones de la Comisión. Por el contrario, «mantener el foco en los principios evita la trampa de un optimismo injustificado en la incidencia y alcance de la convergencia constitucional, sin mencionar el universalismo constitucional» ${ }^{91}$. Según de Visser, la Comisión de Venecia no debería abstenerse de considerar la implementación de principios constitucionales, pero «debería evitar concebir la actuación de tales principios como parte de la herencia común como tal» ${ }^{92}$.

En relación con esta crítica hay tres cuestiones que merecen ser comentadas.

Primero, la línea entre principios constitucionales y su aplicación no siempre es fácil de trazar. Si los principios permanecen en un nivel demasiado elevado de abstracción, hay un riesgo de que se conviertan en envases vacíos, capaces de justificar casi cualquier solución constitucional, democrática y demás. Hay muchos asuntos relacionados con su correcta «aplicación» que son esenciales para el cumplimiento del principio constitucional, y a la inversa, donde tiene poco sentido hablar de tal principio sin considerar la forma de su aplicación.

Segundo, la Comisión de Venecia reconoce las principales preocupaciones subrayadas por de Visser, y siempre lo ha hecho. Los anteriores extractos de miembros de la Comisión y de la Secretaría revelan que se es consciente de las tensiones entre universalidad y pluralidad. Se ha advertido repetidamente contra la idea de que un solo modelo funciona siempre y en cualquier lugar. Se ha articulado la distinción entre estándares hard y soft law, en los que los Estados tienen un mayor margen de apreciación en relación con los últimos. Esto es algo plenamente aceptado por la Comisión y se percibe también en sus opiniones regularmente.

Tercero, la realidad es que cuando los Estados someten asuntos a la Comisión lo hacen precisamente para obtener consejos específicos sobre la aceptabilidad constitucional de leyes concretas. Presentar el modus operandi de la Comisión como el de una organización que impone criterios constitucionales a Estados reticentes 
que perciben a la Comisión como una intrusa de su autonomía es dar una imagen falsa y alejada de la actuación diaria de la Comisión. Las referencias paradigmáticas son aquellas en que los Estados buscan ayuda en relación con una legislación en concreto porque perciben, o les ha sido dicho, que dichas leyes son defectuosas en algunos aspectos. La Comisión es consciente de la necesidad de respetar las diferencias locales y reconoce la legitimidad del pluralismo y la diversidad. La conclusión es, sin embargo, que el Estado busca algo concreto para mejorar su legislación. Además, es instructivo recordar que el incentivo para la Comisión de imbuir conceptos abstractos como el del Estado de Derecho en contenidos más concretos ha venido frecuentemente de nuevas democracias, que esperan obtener consejos específicos sobre lo que entraña el concepto.

\section{LA COMISIÓN DE VENECIA, CUMPLIMIENTO E IMPACTO}

Ya hemos visto antes que el clásico cumplimiento coercitivo no es una condición para la existencia de un OLT o para que una organización pueda ser considerada parte del mismo. El alcance del cumplimiento es, sin embargo, importante, puesto que es un factor que afecta hasta qué punto se puede decir de forma autorizada que las normas legales de ese OLT ordenan la interpretación y práctica de normas en diversas jurisdicciones nacionales.

\section{(a) Cumplimiento y destinatarios}

Los datos sobre el impacto de las opiniones de la Comisión de Venecia en sus destinatarios son desafortunadamente muy escasos, puesto que no hay ningún método sistemático a través del cual la Comisión conozca hasta qué punto se han seguido sus recomendaciones, sin perjuicio del espacio dedicado en las sesiones plenarias para hacer un seguimiento de documentos previamente adoptados. Paradójicamente, estos datos pueden salir a la luz si un Estado se convierte en protagonista reiterado en una misma cuestión. Pero esto no cambia el hecho de que no se dispone de datos sistemáticos sobre el cumplimiento de las recomendaciones de la Comisión. Este problema se podría aliviar fácilmente adoptando la sugerencia de Wolfgang Hoffmann-Riem, quien sugiere que ${ }^{93}$, «como mínimo, aquellos Estados que inician peticiones a la Comisión de Venecia podrían ser obligados a informar, inter alia, sobre la aplicación de las recomendaciones de un modo sistemático, comprensivo y fiable. Lo mismo podría decirse de otros Estados miembro, cuando la petición se haya efectuado por parte de otras autoridades, como la Asamblea Parlamentaria. Además, los miembros que componen la

93 HofFmann-Riem (n 1) 589. 
Comisión nombrados por los Estados podrían colaborar con el Secretariado en la documentación y evaluación del cumplimiento y podrían también ofrecerse al plenum para cuestiones relacionadas.

Esta es una propuesta que tiene mucho sentido. Seguramente habría muchas ocasiones en que los Estados se mostrarían reticentes y no proporcionarían la información requerida, prueba de que el mundo es imperfecto y la Comisión no dispone de ningún mecanismo para obligar al cumplimiento. La propuesta sin embargo contiene una obligación muy clara, y el fracaso en el cumplimiento ya sería indicativo de incumplimiento prima facie y, por tanto, facilitaría ulteriores investigaciones. El simple hecho de que haya divergencias de opinión sobre los niveles de cumplimiento ya indica la necesidad de disponer de mejor información al respecto.

Así, hay quien cree que la correcta aplicación es la tónica general cuando es el Estado el que refiere la cuestión a la Comisión. Esta es la posición de Pieter van $\mathrm{Dijk}^{94}$. Buquicchio y Granata-Menghini comparten esta opinión, ya que indican que «cuando la solicitud de opinión viene de un Estado, lo habitual es que las recomendaciones se sigan, en todo o en parte» ${ }^{95}$. Por el contrario, Hoffmann-Riem considera que esta opinión es «probablemente demasiado optimista» ${ }^{96}$, basándose en datos sobre cumplimiento de opiniones realizadas entre 2009 y mediados de 2012. Su investigación concluyó que algunos Estados solicitantes no adoptaron las recomendaciones, aunque eso era en parte explicable porque «el proyecto enviado a revisión se abandonó o todavía no se había completado, incluyendo la posibilidad de que eso se debiera a las críticas de la Comisión de Venecia», mientras que «en otros casos el proyecto siguió adelante sin tener en cuenta las recomendaciones de la Comisión de Venecia, o al menos la mayoría de ellas» ${ }^{97}$. Hoffmann-Riem, no obstante, también encontró evidencias de que otras opiniones se habían implementado total o parcialmente. Además, también puede haber un elemento temporal relativo al cumplimiento: recomendaciones que son ignoradas por un gobierno en concreto pueden ser retomadas por un ejecutivo ulterior $^{98}$.

Hoffmann-Riem identifica los factores que afectan al cumplimiento, según intuiciones básicas al respecto. El factor más determinante es si el Estado solicitó la opinión, o si fue solicitada por un actor institucional. El cumplimiento es significativamente menos probable en este segundo caso. Este es particularmente el caso si uno añade el factor poder en el Estado afectado y el carácter o la naturaleza

94 VAn Dijk, P. ,'The Venice Commission on Certain Aspects of the European Convention of Human Rights, Ratione Personae', en S. Breitenmoser et al. (eds), Human Rights, Democracy and the Rule of Law: Liber Amicorum Luzius Wildhaber (2007), p. 183, 188.

95 Buquicchio y Granata-Menghini (n 1) 250.

96 HOFFMANN-RIEM (n 1) 589.

97 Ibid 589.

98 Buquicchio - Granata-Menghini (n 1) 248. 
de las opiniones solicitadas por el actor institucional. Ejemplo de esto son las cinco opiniones sobre Rusia elaboradas por la Comisión en 2012 a petición de la Asamblea Parlamentaria del Consejo de Europa. No sólo el Estado destinatario es muy fuerte, sino que las opiniones se centraban en cuestiones muy sensibles como leyes electorales de la Duma ${ }^{99}$, partidos políticos ${ }^{100}$, el derecho de reunión ${ }^{101}$, el combate del extremismo ${ }^{102}$ y el Servicio Federal Ruso de Seguridad ${ }^{103}$. No resulta sorprendente que Rusia se resistiera a introducir algún cambio en esas áreas. Sin embargo, debe admitirse que después de alguna vacilación, Rusia consintió las visitas para la elaboración de las diferentes opiniones y se mostró colaborativa a lo largo de dicho proceso, incluyendo un intercambio de pareceres muy acalorado en la sesión plenaria.

Hay otros factores que también deben tenerse en cuenta a la hora de abordar la cuestión del cumplimiento, tal y como sostiene Hoffmann-Riem. Así, si la Comisión de Venecia se apoya en otras instituciones, como la Comisión Europea, las probabilidades de cumplimiento también aumentan, dado que los Estados suelen preferir no contrariarla. Un factor que inclina la balanza en la otra dirección es cuánto le preocupe al Estado la crítica de la Comisión de Venecia. Si se trata de un Estado autoritario, con poca intención de cambiar y de obtener el imprimatur de Estados más liberales, entonces la opinión seguramente caerá en saco roto ${ }^{104}$.

Los límites al impacto de las opiniones también son explicables en parte por el hecho de que la Comisión «puede analizar y comparar textos legales y sugerir cambios, pero no tiene influencia directa en las condiciones básicas que conducen a la aplicabilidad de la ley en el Estado concernido» ${ }^{105}$. Este punto es importante y tiene amplia resonancia en relación con los límites del impacto transnacional en constituciones nacionales. Los juristas se centran, al menos inicialmente, en el texto y en la procedencia del mismo. Nos preguntamos si hay evidencias de que la constitución de un país ha sido conformada por otras constituciones. Buscamos un nexo de causalidad. Debatimos acerca de la relativa importancia de influencias propias y extranjeras. Esto es una parte importante de la cuestión, pero solo puede ser una parte, por la razón identificada por Hoffmann-Riem. Así, incluso cuando hay una

99 Opinión sobre la Ley Federal sobre la elección de los diputados de la Duma Estatal en la Federación Rusa, CDL-AD(2012)002. Yo fui uno de los ponentes de esta opinión.

100 Opinión sobre la ley de partidos políticos de la Federación Rusa, CDL-AD(2012)003.

101 Opinión sobre la Ley Federal núm. 54-FZ de 19 de junio de 2004 sobre reuniones, manifestaciones, marchas y piquetes de la Federación Rusa, CDL-AD(2012)007.

102 Opinión sobre la Ley Federal sobre el Combate de Actividades Extremistas de la Federación Rusa, CDL-AD(2012)016.

103 Opinión sobre la Ley Federal sobre el Servicio Federal de Seguridad (SFS) de la Federación Rusa, CDL-AD(2012)015.

104 Ver, p.ej., Opinión conjunta sobre la ley de eventos masivos de la República de Bielorusia, CDL-AD(2012)006.

105 HOFFMANN-Riem (n 1) 589. 
aplicación formal de las opiniones de la Comisión de Venecia, la verdadera aplicación dependerá necesariamente de muchos otros factores sociales que afectan la recepción de las normas en tal Estado. Estos incluyen, inter alia, la cultura de gobierno que prevalece, la capacidad y la voluntad burocrática de aplicar las previsiones relevantes, la independencia del poder judicial y el acceso a los tribunales.

\section{(b) Compartiendo las mejores prácticas y cooperación}

La evaluación del impacto de la Comisión no debería, sin embargo, limitarse solo a la consideración de si el Estado aplica o no la opinión dirigida a él. Desde sus inicios la Comisión de Venecia ha operado con un horizonte más amplio, especialmente en países en transición hacia un régimen más democrático y liberal. La Comisión siempre ha reconocido que el cambio no es instantáneo, pero sí puede ser impulsado por otras medidas, incluyendo la capacitación de funcionarios, la organización de seminarios y conferencias, o la involucración de jueces, etc. La Comisión de Venecia dispone de iniciativas en todas estas áreas y aunque es difícil evaluar su impacto real, sería erróneo ignorarlas o subestimarlas ${ }^{106}$. Estas iniciativas son también importantes en países que no son miembros de la Comisión. En este sentido se han desarrollado programas con países del Asia Central, la orilla sur del Mediterráneo y América Latina.

Así, en Asia Central ${ }^{107}$ la Comisión de Venecia ha desarrollado proyectos, algunos de los cuales estaban destinados a países en concreto y otros tenían un alcance regional, en relación con asuntos como asistencia constitucional, justicia constitucional, reforma del poder judicial y legislación y práctica electoral. La dimensión bilateral puede ser ejemplificada por la cooperación, por la que la Comisión suministró asistencia a la recientemente creada Cámara Constitucional del Kyrgyzstan en el campo de la justicia constitucional. Así, la Cámara pidió tal asistencia para entender mejor los estándares internacionales y las mejores prácticas internacionales, puesto que no tenía ninguna experiencia en el ámbito de la justicia constitucional. La dimensión regional de esta cooperación se ejemplifica con la iniciativa Estado de Derecho, del año 2009, promovida de manera conjunta con la UE, que tenía como países destinatarios a los cinco países del Asia Central, Kazajistán, Kyrgyzstán, Tayikistán, Turkmenistán y Uzbekistán. Los objetivos del programa eran, entre otros, fortalecer el Estado de Derecho y la separación de poderes; promover la independencia del poder judicial; asistir en la reforma de la fiscalía; facilitar la integración del derecho internacional en el

106 Ver, p.ej., las diversas iniciativas incluidas en la web de la Comisión de Venecia, http://www. venice.coe.int/webforms/events/.

107 http://www.venice.coe.int/WebForms/pages/?p=03_Central_asia\&lang=EN. 
derecho nacional; reformar la legislación y la administración electorales; y ayudar en la capacitación de jueces y funcionarios.

Las actividades de la Comisión de Venecia en la región sur del Mediterráneo se centraron en proporcionar asistencia y consejo a los países árabes incluso antes de la primavera árabe, estableciéndose estrechos vínculos con Marruecos y Túnez. Estas relaciones pueden tomar la forma de una relación bilateral o de un apoyo regional, como en el caso de Asia Central. Como ejemplo de cooperación bilateral está la asistencia proporcionada, siguiendo una petición de Marruecos en 2014, para la elaboración de dos leyes orgánicas sobre el Alto Consejo Judicial y el Estatuto de los jueces. Un buen ejemplo de cooperación regional es el Campus de la Universidad para la Democracia (UniDem) para los países del Mediterráneo sur $^{108}$. El programa estuvo activo entre los años 2015 y 2017, e incluyó seminarios sobre buena gobernanza, el Estado de Derecho y derechos fundamentales. Los destinatarios fueron altos funcionarios de la región.

La tendencia a cooperar y compartir las mejores prácticas también se da en las relaciones con países de América Latina. Algunos países de la región hoy ya son miembros de la Comisión, como Brasil, Costa Rica, Chile, México y Perú. Las iniciativas de la Comisión destinadas a promover mejores prácticas en ámbitos como transición a la democracia, elaboración de constituciones, justicia constitucional y legislación electoral han sido especialmente relevantes en relación con dichos países. Estas iniciativas han sido promovidas por la Sub-Comisión para América Latina. Compartir las mejores prácticas, sin embargo, no es privativo de Estados que son miembros de la Comisión. Ha habido conferencias con más de veinte países de América Latina y Europa sobre cuestiones como el acceso individual a la justicia constitucional y la implementación de tratados sobre derechos humanos en el ámbito nacional. Además, en el año 2013 tuvo lugar en Ciudad de México el primer encuentro fuera de Venecia de la sub-comisión para América Latina. Al mismo acudieron Estados que no son parte de la Comisión de Venecia.

\section{CONCLUSIÓN}

No pretendo resumir todos los argumentos precedentes. Baste con decir lo siguiente. Deberíamos ser cautelosos con los extremos, especialmente cuando se trata de la evaluación del impacto transnacional de una institución particular en relación con la elaboración de constituciones entendida en sentido amplio. Hay riesgo de sobreestimación, imaginando un efecto transformador que no se puede apoyar en los hechos. Hay igualmente riesgo de subestimación, negando que el cambio puede ser asociado o incluso causado por el trabajo de una institución particular. Deberíamos ser igualmente conscientes de la necesidad de mantener

108 http://www.venice.coe.int/WebForms/pages/?p=03_CampusUniDem\&lang=EN. 
un cierto equilibrio al considerar el trabajo, tanto procedimental como substantivo, de una institución cualquiera. Resulta axiomático que todas las instituciones son imperfectas hasta cierto punto y es por ello que debemos adoptar un escrutinio crítico. Pero por la misma razón también debemos someter las críticas a un cuidadoso examen.

El presente artículo ha pretendido explicar y evaluar el trabajo de la Comisión de Venecia y su impacto en la elaboración transnacional de constituciones, en sentido amplio. El hecho de que se trate de una institución independiente que recurre a los conocimientos legales de miembros altamente cualificados para proporcionar consejos y asistencia a países sobre la compatibilidad de sus constituciones y sus leyes con los principios de democracia, derechos humanos y Estado de Derecho ya es positivo en sí mismo. El hecho de que todos los miembros del Consejo de Europa pertenezcan a la Comisión de Venecia e incluso haya miembros que no son parte de la referida organización contribuye a garantizar el pluralismo y el respeto por las diferencias culturales que es esencial cuando se elaboran las opiniones. Habrá instancias donde inevitablemente haya oposición al contenido de una particular opinión. Siempre ha sido así en este campo. Se ha de reconocer, sin embargo, que la contribución transnacional a las constituciones nacionales puede adoptar diversas formas, desde ayuda en la elaboración de la constitución misma hasta consejos sobre leyes en materia de derechos humanos o desde medidas para garantizar la independencia del poder judicial hasta aquellas previstas para la celebración de elecciones libres y justas. El hecho cierto que la Comisión de Venecia pueda operar sobre todos estos ámbitos ha fortalecido su impacto.

$$
* * *
$$

TITLE: The global constitution-making. The role of the Venice Commission

ABSTRACT: The article describes the origins, the organization, the membership and the role of the Venice Commission and examines its contribution to global constitution-making, the analysis being situated within the literature concerning transnational legal orders. It is concluded that although it cannot be over-estimated, one should not under-estimate either the impact of the Venice Commission in consolidating and strengthening democracy, human rights and Rule of Law in those countries willing to accept the advices of the Commission.

RESUMEN: El artículo describe los orígenes, la composición y el funcionamiento de la Comisión de Venecia y evalúa el impacto que tiene su trabajo en el constitucionalismo global. Dicho análisis se realiza desde la literatura relativa a los órdenes legales transnacionales. Se concluye que aunque no debe exagerarse, tampoco puede menospreciarse el impacto que ha tenido la Comisión de Venecia en la consolidación y el fortalecimiento de la democracia, los derechos humanos y el Estado de Derecho en aquellos países que han querido acogerse a los consejos de la Comisión.

KeY words: Constitutionalism, Venice Commission, Democreacy, Human rigths, Rule of Law.

Palabras Clave: constitucionalismo, órdenes transnacionales, Comisión de Venecia, democracia, derechos humanos, Estado de Derecho.

FECHA DE RECEPCIÓN: 24.02.2017

FECHA DE ACEPTACIÓN: 26.07.2017 
